\title{
Dissolution of Calcidiscus leptoporus coccoliths in copepod guts? A morphological study
}

\author{
Gerald Langer*, Gernot Nehrke, Sandra Jansen
}

Alfred Wegener Institute for Polar and Marine Research, Am Handelshafen 12, 27570 Bremerhaven, Germany

\begin{abstract}
In a dissolution experiment using the calcifying algae Calcidiscus leptoporus the morphological changes of the coccoliths were followed by analysis using scanning electron microscopy. The decrease in coccolith calcite mass during this experiment was quantified. These data were used for the interpretation of coccolith morphologies within faecal pellets produced in separate feeding experiments with the calanoid copepods Calanus helgolandicus and Temora longicornis. Comparison of the observed coccolith morphologies from the coccolith dissolution experiments with the coccolith morphologies observed within the faecal pellets led us to conclude that coccolith dissolution during copepod gut passage is well below 8 weight percent.
\end{abstract}

KEY WORDS: Calcite dissolution · Copepods · Calcidiscus leptoporus · Faecal pellets · SEM

\section{INTRODUCTION}

The production and dissolution of biogenic marine calcite constitutes an important part of the marine carbon and calcium cycle (Milliman 1993, De La Rocha $\&$ DePaolo 2000). In the photic zone, where coccoliths (the calcite platelets of coccolithophores) are produced, no dissolution of calcite can occur, since ocean surface waters are supersaturated with respect to calcite (Zeebe \& Wolf-Gadrow 2001). However, calcite dissolution could occur in a micro-environment undersaturated with respect to calcite. The gut of copepods feeding on coccolithophores for example could provide such an undersaturated environment.

In an experimental study, the mass of coccolith calcite ingested by copepods was compared to the calcite mass egested, and it was shown that up to 73 weight percent (wt.\%) of the coccolith mass was dissolved during gut passage (Harris 1994). In contrast, Jansen \& WolfGladrow (2001) predicted that no significant dissolution would occur under the same experimental conditions (constant feeding). For other grazing conditions, like alternating grazing and non-grazing periods, dissolution of up to 25 wt. \% was predicted by those authors.

Several authors (Roth et al. 1975, Honjo 1976, Honjo \& Roman 1978, Bathmann et al. 1987) made detailed analyses of copepod faecal pellets by means of scan- ning electron microscopy (SEM), which did not reveal signs of coccolith dissolution. From this observation they concluded that the copepod gut is not acidic. The assumption of a non-acidic copepod gut was experimentally confirmed by Pond et al. (1995), who measured gut $\mathrm{pH}$ by means of $\mathrm{pH}$-sensitive fluorescent dye. Using this method they reported $\mathrm{pH}$ values of $\sim 7$ for starved specimens and $\sim 8$ for specimens fed with coccolithophores. Even though several authors investigated coccolith dissolution during copepod gut passage, the methods used were diverse, making it difficult to compare results directly. The interpretation of SEM images with respect to coccolith dissolution is difficult, since no data are available relating morphological data to numbers in terms of weight percent calcite dissolution.

To fill this gap we have performed a dissolution experiment with coccospheres of the widespread species Calcidiscus leptoporus. Research so far has focused on Emiliania huxleyi, a bloom-forming species. Data from copepod feeding experiments (Roth et al. 1975, Harris 1994, Nejstgaard et al. 1994, 1997), as well as a dissolution experiment showing graded dissolution of coccoliths (McIntyre \& McIntyre 1971), are available. However, morphological data were not related to calcite mass loss. C. leptoporus is at least as important as E. huxleyi in terms of calcite export 
production (Sprengel et al. 2000, Baumann et al. 2004). Moreover, C. leptoporus is more resistant to dissolution than E. huxleyi (McIntyre \& McIntyre 1971, Berger 1973). Hence, data on dissolution of C. leptoporus coccoliths are desirable. In our study the morphological changes during $C$. leptoporus coccolith dissolution were followed by means of SEM analysis and correlated to the observed mass loss. These data were used for the interpretation of coccolith morphologies within the faecal pellets produced in additionally conducted feeding experiments with the copepods Calanus helgolandicus and Temora longicornis.

\section{MATERIALS AND METHODS}

Dissolution experiments using Calcidiscus leptoporus. A monospecific culture of C. leptoporus (Strain AC365, from the South Atlantic off South Africa, CODENET culture collection, ALGOBANK www.nhm. ac.uk/hosted_sites/ina/CODENET/caencultures.htm) was grown in sterile, filtered $(0.2 \mu \mathrm{m})$ seawater, enriched with $100 \mu \mathrm{M}$ nitrate, $6.25 \mu \mathrm{M}$ phosphate, trace metals and with vitamins according to f/2 (Guillard \& Ryther 1962). The incident photon flux density was $350 \mu \mathrm{mol} \mathrm{m}{ }^{-2} \mathrm{~s}^{-1}$, and a 12:12 h light:dark cycle was applied. Cells were grown at optimum growth temperature, i.e. $20^{\circ} \mathrm{C}$. For determination of cell density, samples were counted immediately after sampling using a Sedgwick Rafter counting cell. Cells were grown to a density of $\sim 2500$ cells $\mathrm{ml}^{-1}$ and then put in an oven at $45^{\circ} \mathrm{C}$ for $10 \mathrm{~h}$ in order to kill the cells. Previous tests showed that cell density remained constant after heat treatment, and SEM observations showed that the morphology of the coccoliths did not change.

At the start and end of the experiment, alkalinity and dissolved inorganic carbon (DIC) were measured. Total alkalinity was calculated from linear Gran plots (Gran 1952) after duplicate potentiometric titration (Bradshaw et al. 1981, Brewer et al. 1986), and DIC was measured in triplicate using a Shimadzu TOC 5050A analyser. For alkalinity measurements, samples were sterile filtered $(0.2 \mu \mathrm{m})$ and stored in $300 \mathrm{ml}$ borosilicate flasks at $0^{\circ} \mathrm{C}$. DIC samples were sterile filtered and stored in $6 \mathrm{ml}$ borosilicate flasks free of air bubbles at $0^{\circ} \mathrm{C}$.

The carbonate system was calculated from temperature, salinity, and the concentrations of DIC, total alkalinity and phosphate, using the program $\mathrm{CO}_{2}$ sys (Lewis \& Wallace 1998). The equilibrium constants by Mehrbach et al. (1973) and refitted by Dickson \& Millero (1987) were chosen.

The calcite saturation state $\left(\Omega=\right.$ IAP $K^{-1}$, where IAP is the ion activity product of $\mathrm{Ca}^{2+}$ and $\mathrm{CO}_{3}{ }^{2-}$ and $K$ the solubility constant of calcite) was adjusted by adding calculated amounts of $1 \mathrm{M} \mathrm{HCl}$ to the medium. The total volume of the cell culture was then subdivided into separate flasks. In order to prevent gas exchange with the atmosphere, 0.61 borosilicate flasks were filled without headspace and closed with Teflon-lined screw caps. The flasks were continuously rotated on a plankton wheel at $15^{\circ} \mathrm{C}$ in order to prevent sedimentation. At distinct points in time the contents of 1 flask were filtered on preweighted, $25 \mathrm{~mm}$ polycarbonate (PC) filters, with a pore size of $0.8 \mu \mathrm{m}$. The PC filters were dried in a drying cabinet at $60^{\circ} \mathrm{C}$ for $12 \mathrm{~h}$ and then weighed on a Mettler Toledo UMX2 micro-balance. The reduction in total cell mass per filter was used as a measure for calcite loss through dissolution. Therefore, it is required that cell densities can be related linearly to cell mass. This was tested by preparing solutions with different cell densities in triplicate. The result of this test is presented in Fig. 1. Besides calcite mass, total cell mass also includes protoplast mass. If organic components were destroyed as well during calcite dissolution, a part of the observed reduction in total cell mass per filter could be attributed to loss of organic material. In order to estimate the mass percentage of calcite and organic material of Calcidiscus leptoporus cells, we measured particulate organic carbon (POC, 60 pg cell ${ }^{-1}$ ) and particulate inorganic carbon (PIC, $\sim 140$ pg cell ${ }^{-1}$ ) per cell in samples from another batch of cells grown under identical conditions. Therefore, samples for determination of total particulate carbon (TPC) and POC were filtered on precombusted $\left(12 \mathrm{~h}, 500^{\circ} \mathrm{C}\right) \mathrm{GF} / \mathrm{F}$-filters $(0.6 \mu \mathrm{m})$ and stored at $-20^{\circ} \mathrm{C}$ until further handling. Prior to analysis, the POC filters were fumed for $2 \mathrm{~h}$ with a saturated $\mathrm{HCl}$ solution to remove all inorganic carbon. TPC and POC were subsequently measured on a Carlo Erba

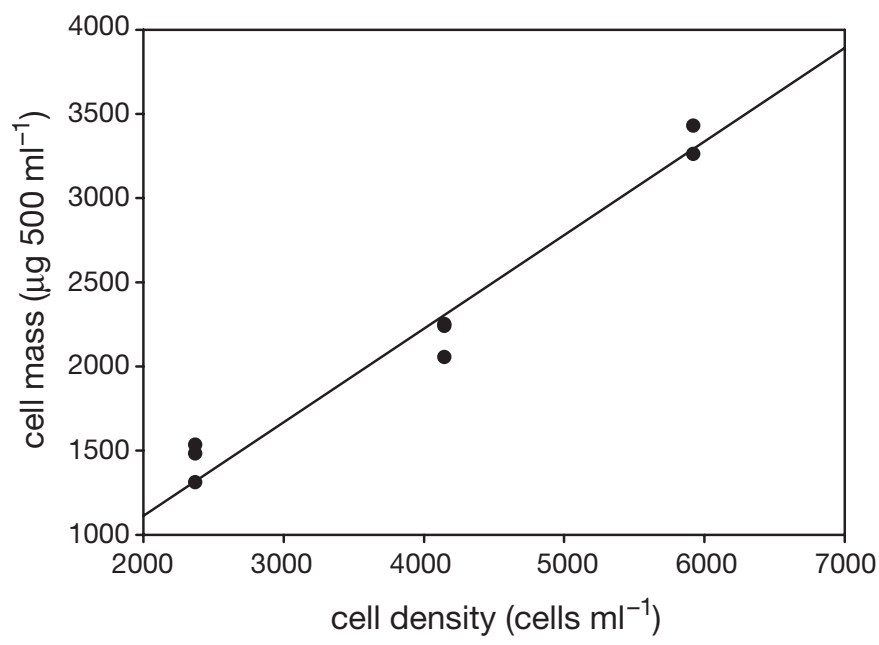

Fig. 1. Calcidiscus leptoporus. Dependence of cell mass on cell density 
NA-1500 Analyser. PIC was calculated as the difference between TPC and POC. Assuming that $50 \mathrm{wt} \%$ of the protoplast dry mass is carbon mass, we calculated the mass of the organic material to be $\sim 120 \mathrm{pg}$ cell $^{-1}$. Thus, 90 wt. $\%$ of total cell mass is calcite. The filters used for the determination of the mass loss during dissolution were subsequently prepared for SEM analysis. Therefore, it was not possible to determine TPC and POC for each filter. However, the values in Fig. 2 are based on total cell mass, the reduction of which might include dissolution of organic material. As shown above, up to $10 \mathrm{wt}$ \% of the total cell mass is organic material. If dissolution of organic material occurred during the experiment, the calculated values for loss of calcite mass would be an overestimation.

SEM micrographs of the filtered samples were taken using a Quanta 200F/FEI. Therefore, the filters were cut into smaller pieces and fixed with double-sided carbon tape on aluminium stubs. The stubs were coated with platinum/palladium using an Emscope SC500 sputter coater.

Faecal pellet production experiments. Faecal pellet production experiments were carried out using a mixture of Calcidiscus leptoporus and Thalassiosira weissflogii as food. C. leptoporus and T. weissflogii were grown in $f / 2$ medium (Guillard \& Ryther 1962), in a temperature-controlled room at 20 and $15^{\circ} \mathrm{C}$, respectively. For faecal pellet production experiments, algae were mixed to achieve an end concentration of $1300 \mu \mathrm{C} \mathrm{Cl}^{-1}$. A mixture of 1:3 with regard to cell numbers was chosen, corresponding to 1390 cells C. leptoporus $\mathrm{ml}^{-1}$ and 4590 cells $T$. weissflogii $\mathrm{ml}^{-1}$.

Copepods were collected close to Helgoland with a $180 \mu \mathrm{m}$ net, slowly towed from $15 \mathrm{~m}$ to the surface. After retrieval, copepods were diluted in $10 \mathrm{l}$ of surface water, and adult females of Calanus helgolandicus and Temora longicornis were sorted out in a temperature-controlled room at $15^{\circ} \mathrm{C}$. They were then transferred to $1 \mathrm{l}$ bottles containing the experimental concentration of algae for overnight acclimatisation on a so-called plankton wheel that slowly rotated in a room at $15^{\circ} \mathrm{C}$. The rotating wheel maintained even distributions of food particles. After $16 \mathrm{~h}$, females were carefully transferred to $250 \mathrm{ml}$ beakers filled with the same algal mixture used during acclimatisation. For both copepod species C. helgolandicus and T. longicornis, 5 replicates were set up, including 2 or 3 specimens each, respectively. Faecal pellet production experiments were carried out for a total of $6 \mathrm{~h}$, while beakers were checked once an hour for faecal pellets, which were directly enumerated and picked out to prevent coprophagy. Faecal pellet production rates were calculated, and faecal pellets were prepared for SEM analysis (Wexels Riser et al. 2003).

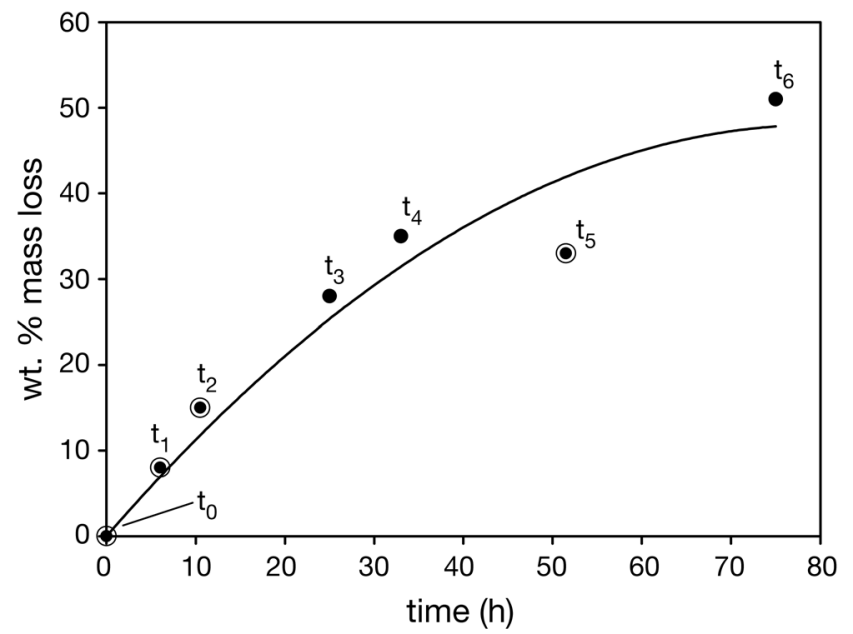

Fig. 2. Calcidiscus leptoporus. Development of mass loss in the course of the dissolution experiment. The encircled dots mark the points in time at which the coccolith morphologies were investigated by SEM (see Fig. 3)

\section{RESULTS AND DISCUSSION}

\section{Dissolution data}

Dead cells of Calcidiscus leptoporus were exposed to seawater undersaturated with respect to calcite $(\Omega=$ $0.5)$ for different time spans. The decrease in calcite mass during this experiment is shown in Fig. 2. The morphologies present at distinct points in time (encircled points in Fig. 2) are presented in Fig. 3. At the start of the experiment coccoliths display, apart from the usual culture artefacts, a normal morphology. It is well known that malformations are more abundant in culture samples than in oceanic samples.

Since the general reader might not be familiar with coccolith morphology, we briefly explain the morphology of Calcidiscus leptoporus coccoliths. A coccolith comprises 2 shields: the proximal and the distal shield (Fig. 4A). The coccosphere, i.e. the shell of the coccolithophore cell, is built of roughly 20 interlocking coccoliths (Fig. 4B). For detailed description of terminology see Young et al. (1997).

The typical coccolith morphology present at the onset of the experiment ( $t_{0}$, Fig. 2$)$ is shown in Fig. 3A, while a more detailed view of this morphology (Fig. 3B) shows a coccolith in proximal view and one in distal view. With a weight loss of $8 \%\left(t_{1}\right.$, Fig. 2$)$, the detachment of the distal and proximal shield can be observed throughout the whole sample and is thus representative for this early stage of dissolution (Fig. 3C,D). As dissolution proceeds (15 to $33 \mathrm{wt} \%$ ), the detached proximal and distal shields fall apart (Fig. 3E,F). Roth \& Berger (1975) reported coccoliths of Calcidiscus leptoporus in surface sediments, some 

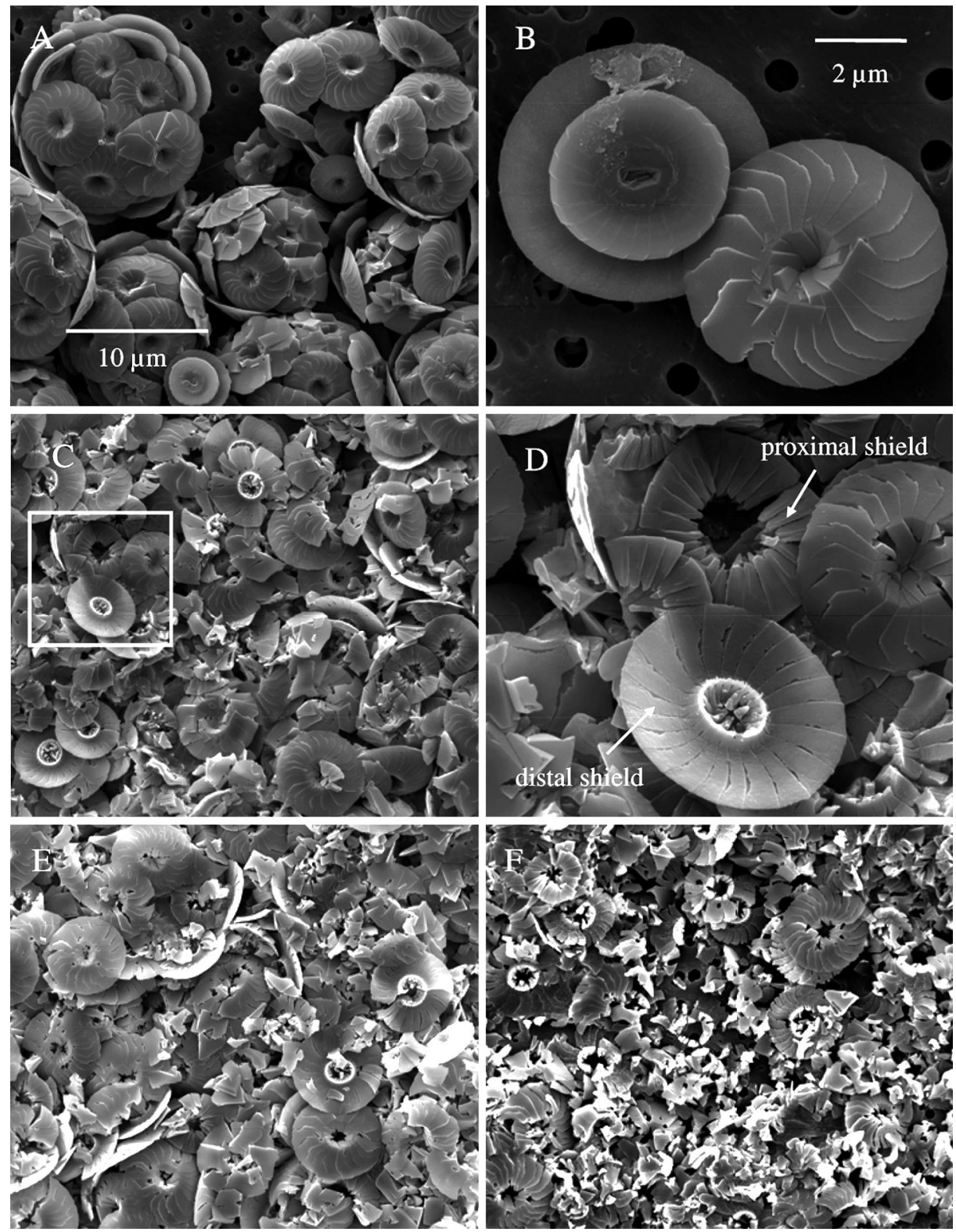

Fig. 3. Calcidiscus leptoporus. Morphological changes during the dissolution of $C$. leptoporus at distinct points in time marked in Fig. 2. (A) At time $t_{0}$ the sample is dominated by complete coccospheres, with coccoliths showing no signs of dissolution (slightly elongated spheres result from the filtration procedure). (B) Detailed view of a typical coccolith at $t_{0}$ in proximal (left) and distal view (right). (C) At time $t_{1}$ all proximal and distal shields are detached. (D) Close-up of the marked area in (C), showing detached proximal and distal shields. A few shields have already disintegrated (example in the lower right). (E,F) SEM micrographs taken at times $t_{2}$ and $t_{5}$, respectively, show later stages of dissolution characterised by more distinct disintegration of detached shields

of them lacking proximal shields. They interpreted the detachment of the shields as a sign of heavy dissolution. We regard this characteristic feature as an indicator of an early dissolution stage, which already appears at $<8$ wt. $\%$ dissolution. In the following discussion of the copepod faecal pellet production experiments, we have therefore placed special emphasis on single shields in faecal pellets.

\section{Dissolution of Calcidiscus leptoporus within copepod faecal pellets?}

Calanus helgolandicus and Temora longicornis feeding on a monoculture of Calcidiscus leptoporus $\left(\sim 6000\right.$ cells $\left.\mathrm{ml}^{-1}\right)$ resulted in faecal pellets that were notably fragile. Only 1 faecal pellet produced by C. helgolandicus could be prepared for SEM analysis 

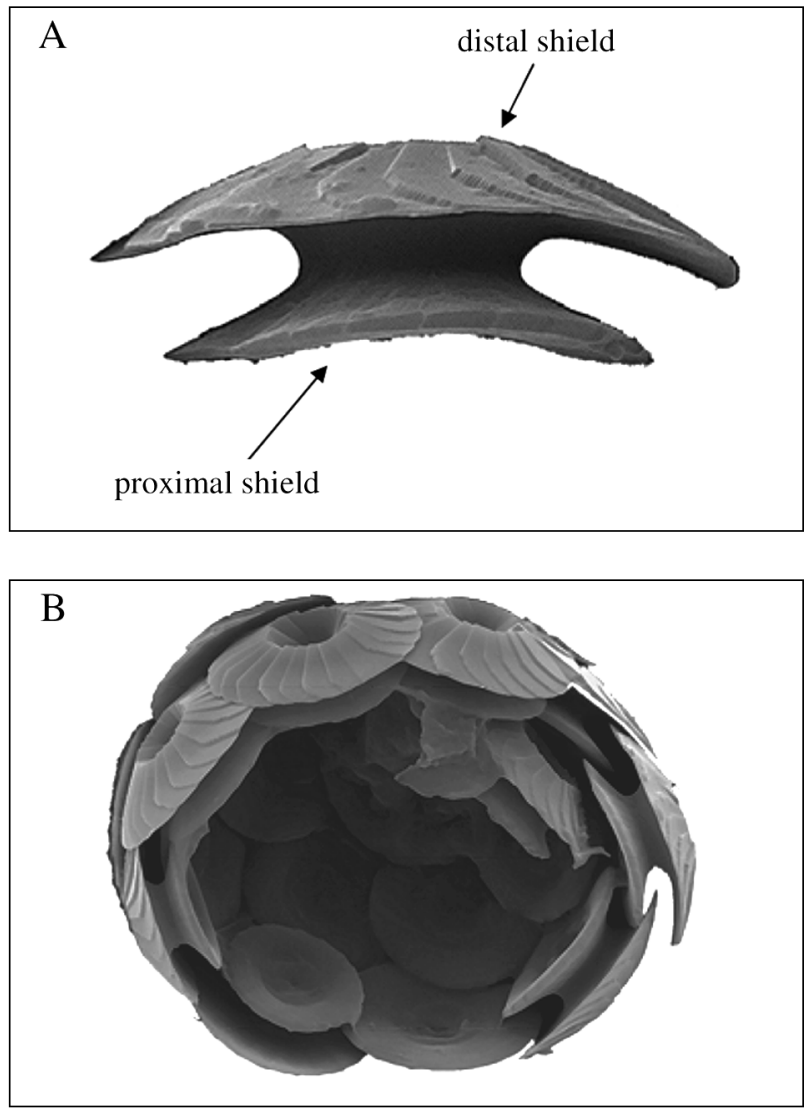

Fig. 4. Calcidiscus leptoporus. General morphology. (A) Side view of a coccolithophore lith (coccolith) built up by distal and proximal shield. (B) An open coccosphere, i.e. the shell of the coccolithophore cell, built of roughly 20 interlocking coccoliths

(Fig. 5A,B). It is not clear whether the peritrophic membrane of the faecal pellets is lacking when copepods feed on C. leptoporus monoculture, but a lack or instability of the peritrophic membrane could possibly explain the observed fragility of the faecal pellets. To increase the stability of the faecal pellets, experiments were repeated with a mixture of C. leptoporus and the diatom Thalassiosira weissflogii. Faecal pellets remained stable and complete during further handling.

SEM observations of the faecal pellets produced were used to compare coccolith morphologies from dissolution experiments (Fig. 3), with the coccoliths within the faecal pellets (Fig. 5). Pictures show coccoliths in a faecal pellet of Calanus helgolandicus, feeding on a monoculture of Calcidiscus leptoporus (Fig. 5B) and from the same species feeding on a mixture of C. leptoporus and Thalassiosira weissflogii (Fig. 5C). The coccoliths in these faecal pellets did not display detached shields. It has to be noted that, especially in Fig. 5B, all coccoliths in lateral view clearly comprise both distal and proximal shields. The same holds true for faecal pellets produced by Temora longicornis (Fig. 5D). In general, all coccoliths observed comprised both shields. However, some coccoliths showed signs of damage, which can be clearly interpreted as mechanical destruction caused by the mandibles of the copepod. This can safely be concluded from the following observations: partially dissolved coccoliths show detached shields, while the shields themselves are not broken (Fig. 3). In mechanically destroyed coccoliths, on the other hand, the shields are broken and mostly not detached from one another (Fig. 5). This interpretation is supported by copepod feeding experiments carried out by Roth et al. (1975), where mechanically destroyed coccoliths were also described.

From the calcite mass loss curve (Fig. 2), in combination with our SEM analysis, we can conclude that $<8$ wt.\% of Calcidiscus leptoporus calcite is dissolved in the gut of the investigated copepod species Calanus helgolandicus and Temora longicornis at the given faecal pellet production rates. As already explained in 'Materials and methods', the values in Fig. 2 do not account for loss of organic material. Therefore, the value of $8 \mathrm{wt}$. \% has to be regarded as an absolute maximum value, and the true value is probably much smaller. C. helgolandicus produced $2.9 \pm 0.3$ faecal pellets female $\mathrm{f}^{-1}$, while the production rate of T. longicornis was calculated to be $4.1 \pm 0.5$ faecal pellets female $\mathrm{e}^{-1} \mathrm{~h}^{-1}$. The faecal pellet production rate can be used to estimate gut passage times. Assuming that the gut volume is equivalent to 2 faecal pellets, gut passage time is twice the interval between the production of a single pellet (Mauchline 1998). Therefore, estimated gut passage times for $C$. helgolandicus and T. longicornis in the present study were about 30 and $40 \mathrm{~min}$, respectively. Gut passage times of 30 to $40 \mathrm{~min}$ were also observed in a number of other species (Arashkevich 1977), and Jansen \& Wolf-Gladrow (2001) chose 30 min as a representative value in their model.

In a number of studies, faecal pellets were analysed by means of SEM, most of them containing well-preserved coccoliths that showed no signs of dissolution (Roth et al. 1975, Honjo 1976, Honjo \& Roman 1978, Bathmann et al. 1987). The question remained, however, at which dissolution stage (i.e. wt.\% calcite dissolved) can partial dissolution of coccoliths be recognised in SEM images. Since different coccolithophore species were used in the above-mentioned studies, it is not straightforward to apply our correlation between mass loss and morphology to these data directly. Most experimental and field studies focused on the coccolithophore species Emiliania huxleyi. 

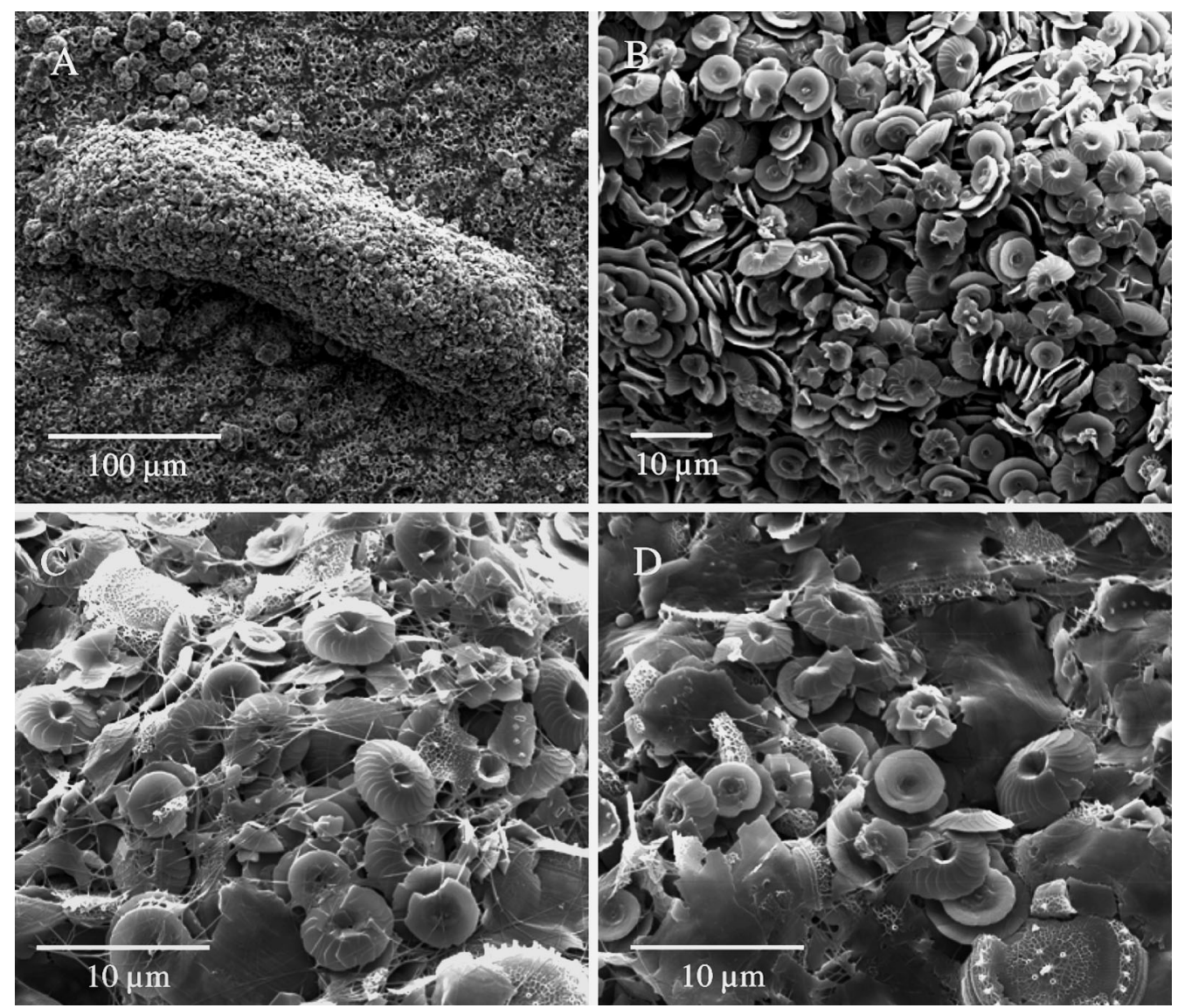

Fig. 5. (A) Faecal pellet produced by Calanus helgolandicus while feeding on a monoculture of Calcidiscus leptoporus. (B) Detailed view of the coccoliths within the faecal pellets shown in the previous image. Faecal pellet of (C) C. helgolandicus and

(D) Temora longicornis containing Thalassiosira weissflogii and C. leptoporus. It is noted that all coccoliths in lateral view clearly comprise both distal and proximal shields

McIntyre \& McIntyre (1971) showed that E. huxleyi coccoliths display partially dissolved central areas in a very early dissolution stage. Unfortunately, they did not quantify the mass loss associated with the changing morphologies. However, since Calcidiscus leptoporus is more resistant to dissolution than E. huxleyi (Berger 1973) and 8 wt.\% dissolution is clearly visible in our experiments, it is likely that this holds true for other species, especially for more soluble ones like E. huxleyi. Thus, we conclude that coccolithophore calcite dissolution in the gut of copepods in general is $<8 \mathrm{wt} . \%$. This assumption is supported by a numerical model by Jansen \& Wolf-Gladrow (2001) stating that under conditions comparable to those in our experiments (constant feeding) no significant dissolution should occur.

To our knowledge only 1 study states that significant coccolith dissolution occurs during copepod gut passage (Harris 1994). In that study (Harris 1994), where Pseudocalanus elongatus and Calanus hel- golandicus were grazing on Emiliania huxleyi, 50 to 73 wt.\% of the ingested coccoliths were not egested. The author concludes that this considerable loss is due to acid digestion in the copepod gut. Harris (1994) states that the high mass loss he reports is in conflict with SEM observations presented in the literature. The author gives 3 possible explanations for this discrepancy: firstly, intact coccoliths observed by means of SEM are only those which have escaped dissolution; secondly, incomplete quantitative recovery of faecal pellets (i.e. underestimation of egestion); and, thirdly, 'sloppy feeding' (i.e. overestimation of ingestion). Since our dissolution experiment showed that dissolution proceeds homogeneously throughout the whole sample, i.e. affecting all coccolith simultaneously, we would expect to find partially dissolved coccoliths in a faecal pellet if significant amounts of coccoliths were dissolved in copepod guts. Therefore, our results do not confirm the first explanation of Harris (1994). The fact that the author used a monoculture as food, how- 
ever, could render the second explanation likely, because in our feeding experiments we could hardly recover 1 faecal pellet containing exclusively Calcidiscus leptoporus coccoliths, since they were fragile. If this holds true also for E. huxleyi monoculture, it could possibly explain the high apparent dissolution in the study of Harris (1994). The third explanation given by Harris (1994), i.e. 'sloppy feeding' should result in considerable amounts of loose coccoliths floating in the bottles. Large amounts of loose coccoliths are generally not observed in C. leptoporus cultures, because this species does not shed coccoliths like E. huxleyi; thus, only complete coccospheres are usually present. We could not find high numbers of loose coccoliths on the filters containing the faecal pellets. However, this observation is not sufficient to exclude 'sloppy feeding', since the volume of water on theses filters is not representative (see 'Materials and methods').

The latter discussion renders it most likely that the massive dissolution reported by Harris (1994) represents an overestimation. Considering our findings in context with other studies (see above), there are good reasons to assume that only insignificant dissolution of coccoliths during copepod gut passage occurs.

\section{CONCLUSIONS}

SEM observations on the dissolution of Calcidiscus leptoporus showed that the detachment of the proximal and the distal shield of a coccolith is an early stage in the dissolution process, which is readily observable at 8 wt. \% dissolution.

This result was used to interpret the morphology of Calcidiscus leptoporus coccoliths within freshly produced faecal pellets of the copepods Calanus helgolandicus and Temora longicornis. Since no detached shields were found in faecal pellets, it was concluded that $<8 \mathrm{wt} . \%$ of $C$. leptoporus calcite was dissolved during gut passage of the investigated copepod species. It might be concluded that calcite dissolution above the lysocline is generally not mediated by copepods.

Acknowledgements. The authors thank C. Augustin for providing the copepods. We thank Tom Noji and 2 anonymous reviewers for valuable comments that helped improve the manuscript. G.L. acknowledges financial support by the Helmholtz-Gemeinschaft Deutscher Forschungszentren (Project HZNG102). The work was supported by the German Research Foundation (DFG) and is part of Project BI 432/3-2. It was also supported by the DFG under Grant Nos. BI 432/32, BI 432/4-2 ('PaleoSalt'), BI 432/6-1 ('BioCalc') and by the European Science Foundation (ESF) under the EUROCORES Programmes EuroCLIMATE and EuroMinScI, through Contract No. ERAS-CT-2003-980409 of the European Commission, DG Research, FP6.

\section{LITERATURE CITED}

Arashkevich EG (1977) Duration of food digestion in marine copepods. Pol Arch Hydrobiol 24:431-438

Bathmann UV, Noji TT, Voss M, Peinert R (1987) Copepod fecal pellets: abundance, sedimentation and content at a permanent station in the Norwegian Sea in May/June 1986. Mar Ecol Prog Ser 38:45-51

Baumann KH, Böckel B, Frenz M (2004) Coccolith contribution to South Atlantic carbonate sedimentation. In: Thierstein HR, Young JR (eds) Coccolithophores - from molecular processes to global impact. Springer-Verlag, Berlin, p 367-402

Berger WH (1973) Deep-sea carbonates: evidence for a coccolith lysocline. Deep-Sea Res 20:917-921

Bradshaw AL, Brewer PG, Shaffer DK, Williams RT (1981) Measurements of total carbon dioxide and alkalinity by potentiometric titration in the GEOSECS program. Earth Planet Sci Lett 55:99-115

Brewer PG, Bradshaw AL, Williams RT (1986) Measurement of total carbon dioxide and alkalinity in the North Atlantic Ocean in 1981. In: Trabalka JR, Reichle DE (eds) The changing carbon cycle-a global analysis. SpringerVerlag, New York, p 358-381

De La Rocha C, DePaolo DJ (2000) Isotopic evidence for variations in the marine calcium cycle over the Cenozoic. Science 289:1176-1178

Dickson AG, Millero FJ (1987) A comparison of the equilibrium constants for the dissociation of carbonic acid in seawater media. Deep-Sea Res 34:1733-1743

Gran G (1952) Determination of the equivalence point in potentiometric titrations of seawater with hydrochloric acid. Oceanol Acta 5:209-218

Guillard RRL, Ryther JH (1962) Studies of marine planktonic diatoms. I. Cyclotella nanna (Hustedt) and Detonula convervacea (Cleve). Can J Microbiol 8:229-239

Harris RP (1994) Zooplankton grazing on the coccolithophore Emiliania huxleyi and its role in inorganic carbon flux. Mar Biol 119:431-439

Honjo S (1976) Coccoliths: production, transportation and sedimentation. Mar Micropaleontol 1:65-79

Honjo S, Roman MR (1978) Marine copepod fecal pellets: production, preservation and sedimentation. J Mar Res 36: $45-57$

Jansen H, Wolf-Gladrow DA (2001) Carbonate dissolution in copepod guts: a numerical model. Mar Ecol Prog Ser 221: 199-207

Lewis E, Wallace DWR (1998) Program developed for $\mathrm{CO}_{2}$ system calculations ORNL/CDIAC-105. Carbon Dioxide Information Analysis Centre, Oak Ridge National Laboratory, U.S. Department of Energy, Oak Ridge, TN

Mauchline J (1998) The biology of calanoid copepods. Academic Press, London

McIntyre A, McIntyre R (1971) Coccolith concentration and differential solution in oceanic sediments. In: Funnel BM, Riedel WR (eds) The micropaleontology of oceans. Cambridge University Press, Cambridge, p 253-261

Mehrbach C, Culberson CH, Hawley JE, Pytkovicz RM (1973) Measurement of the apparent dissociation constants of carbonic acid in seawater at atmospheric pressure. Limnol Oceanogr 18:897-907

Milliman JD (1993) Production and accumulation of calcium carbonate in the ocean: budget of a nonsteady state. Global Biogeochem Cycles 7:927-957

Nejstgaard JC, Witte HJ, van der Wal P, Jacobsen A (1994) Copepod grazing during a mesocosm study of an Emiliania huxleyi (Prymnesiophyceae) bloom. Sarsia 79:369-377 
Nejstgaard JC, Gismervik I, Solberg PT (1997) Feeding and reproduction by Calanus finmarchicus, and microzooplankton grazing during mesocosm blooms of diatoms and the coccolithophore Emiliania huxleyi. Mar Ecol Prog Ser 147:197-217

Pond DW, Harris RP, Brownlee C (1995) A microinjection technique using a $\mathrm{pH}$-sensitive dye to determine the gut pH of Calanus helgolandicus. Mar Biol 123:75-79

Roth PH, Berger WH (1975) Distribution and dissolution of coccoliths in the south and central Pacific. In: Sliter WV, Be $\mathrm{AWH}$, Berger $\mathrm{WH}$ (eds) $\mathrm{CaCO}_{3}$ dissolution in the deep sea. Cushman Foundation for Foraminiferal Research, Santa Barbara, CA, p 87-113

Roth PH, Mullin MM, Berger WH (1975) Coccolith sedimentation by fecal pellets: laboratory experiments and field observations. Geol Soc Am Bull 86:1079-1084

Editorial responsibility: Otto Kinne (Editor-in-Chief), Oldendorf/Luhe, Germany
Sprengel C, Baumann KH, Neuer S (2000) Seasonal andinterannual variation of coccolithophore fluxes and species composition in sediment traps north of Gran Canaria $\left(29^{\circ} \mathrm{N}, 15^{\circ} \mathrm{W}\right)$. Mar Micropaleontol 39:157-178

Wexels Riser C, Jansen S, Bathmann U, Wassmann P (2003) Grazing of Calanus helgolandicus on Dinophysis norvegica during bloom conditions in the North Sea: evidence from investigations of faecal pellets. Mar Ecol Prog Ser 256:301-304

Young JR, Bergen JA, Bown PR, Burnett JA and 6 others (1997) Guidelines for coccolith and calcareous nannofossil terminology. Palaeontology 40:875-912

Zeebe RE, Wolf-Gadrow DA (2001) $\mathrm{CO}_{2}$ in seawater: equilibrium, kinetics, isotopes, Vol 65. Elsevier Oceanography Series, New York

Submitted: February 28, 2006; Accepted: July 10, 2006 Proofs received from author(s): February 6, 2007 